\title{
Measuring Duodeno-Gastric and Duodeno-Gastro-Esophageal Reflux in Clinical Practice: The Role of Age
}

\author{
J. Tack \\ Center for Gastroenterological Research, University Hospital Gasthuisberg, Leuven, Belgium
}

The pathological role of acid reflux to the esophagus in gastro-esophageal reflux disease (GERD) is well established: typical symptoms of heartburn are mimicked by esophageal acid perfusion [1], esophageal $\mathrm{pH}$ monitoring is used to quantify GERD [2] and acid-suppressive drugs are the cornerstone of medical treatment [3]. There is now an increasing body of evidence that duodeno-gastroesophageal reflux (DGER) is also involved in the pathophysiology of GERD.

The occurrence of erosive esophagitis in patients with achlorhydria and after total gastrectomy $[4,5]$ argues in favor of a role for reflux of duodenal content in the pathogenesis of erosive esophagitis. The use of prolonged fiberoptic monitoring of bilirubin concentration $\left(\right.$ Bilitec $^{\circledR}$ ) has allowed quantifying reflux of duodenal content to the stomach and the esophagus. Bilitec ${ }^{\circledR}$ studies have shown that DGER is more common in patients with severe esophagitis and Barrett's esophagus than in patients without or with minor esophagitis $[6,7]$. It is clear that duodeno-gastric reflux (DGR) is a prerequisite for DGER to occur, and a recent study has shown that DGR is a physiological phenomenon in the postprandial period and occurs sporadically in the interdigestive state [8].

In order to study the role of acid reflux, DGR and DGER in disease, knowledge of the normal range of gastric and esophageal exposure is required. Studies on the influence age on esophageal $\mathrm{pH}$ monitoring showed conflicting results, although there is a clear tendency for in- creased acid exposure with age $[9,10]$. In the present issue of Digestion, Bollschweiler et al. [11] compared normal values for DGR and DGER exposure in younger and older asymptomatic volunteers. The authors found that older volunteers ( $>40$ years old) had higher DGER exposure compared to younger volunteers, but they reported no differences in DGR exposure.

Comparison of studies investigating DGR in the literature is hampered by the use of different positions of the probe (antrum vs. fundus), the use of different cut-offs for bilirubin absorbance, and the use of different dietary interventions to avoid food impaction artifacts [6-8]. Bollschweiler et al. [11] studied DGR exposure $10 \mathrm{~cm}$ distal to the LES in subjects on a white diet, and comparing DGR values at different cut-offs, they found no agerelated differences.

When assessing esophageal bilirubin exposure, the authors found significantly higher DGER values in older volunteers. In the absence of a difference in gastric exposure, these findings suggest that age-related changes in esophageal motility or in competence of the esophagogastric junction underlie the higher DGER exposure in older subjects. Peristalsis is the only clearance mechanism for DGER [12], but decreases in peristaltic function with age in asymptomatic subjects are subtle and probably of minimal impact [13]. The incidence of hiatal hernia clearly increases with age, and this is potentially an important contributor to higher levels of duodenal content

\section{KARGER \\ Fax +4161306 1234 E-Mail karger@karger.ch} www.karger.com
(C) 2005 S. Karger AG, Basel 0012-2823/05/0712-0063\$22.00/0

Accessible online at: www.karger.com/dig
Jan Tack, MD, PhD

Department of Internal Medicine, Division of Gastroenterology

University Hospital Gasthuisberg, 49, Herestraat

BE-3000 Leuven (Belgium)

Tel. +32 16 344225, Fax +3216344419, E-Mail Jan.tack@med.kuleuven.ac.be 
exposure with age [14]. Unfortunately, the authors did not assess the presence of small hiatal hernias with endoscopy or radiography in their group of healthy controls.

There are very few, if any, clinical applications of intragastric bilirubin monitoring, but several studies suggest usefulness of esophageal Bilitec ${ }^{\circledR}$ monitoring in the evaluation of difficult or refractory GERD patients $[6,7$, 15]. The paper by Bollschweiler et al. [11] demonstrates that upper limits of normal may be higher in subjects $>40$ years, which is likely to be the majority of the patients. It is unclear whether DGER exposure would be even higher in those older than 60 or 70 years. Furthermore, there is a major variability of normal ranges of esophageal DGER exposure across the literature, and dietary habits or restrictions have a major impact on DGER exposure values $[7,11]$. Clinicians should therefore be careful when considering to take major management decisions, like referral for surgery, on the basis of Bilitec ${ }^{\circledR}$ studies. Based on the multiple factors that influence esophageal DGER exposure, each center will probably have to establish its own normal values, not only for younger but also for older subjects.

\section{References}

1 Smith JL, Opekun AR, Larkai E, Graham DY: Sensitivity of the esophageal mucosa to $\mathrm{pH}$ in gastroesophageal reflux disease. Gastroenterology 1989;96:683-688.

2 Kahrilas PJ, Quigley EM: Clinical esophageal pH recording: A technical review for practice guideline development. Gastroenterology 1996;110:1982-1996.

3 Tytgat GN: Review article: Management of mild and severe gastro-esophageal reflux disease. Aliment Pharmacol Ther 2003;17(suppl 2):52-56.

4 Helsingen N: Esophagitis following total gastrectomy. Acta Chir Scand 1957;118:190201.

5 Palmer ED: Subacute erosive peptic esophagitis associated with achlorhydria. N Engl J Med 1960;262:927-929.
6 Champion G, Richter JE, Vaezi MF, et al: Duodeno-gastro-esophageal reflux: Relationship to $\mathrm{pH}$ and importance in Barrett's esophagus. Gastroenterology 1994;107:747-754.

7 Tack J, Bisschops R, Koek GH, Sifrim D, Lerut T, Janssens J: Dietary restrictions during ambulatory monitoring of duodeno-gastroesophageal reflux Dig Dis Sci 2003;48:12131220.

8 Koek GH, Vos R, Sifrim D, Cuomo R, Janssens J, Tack J: Mechanisms underlying duodenogastric reflux in man. Neurogastroenterol Motil 2005; in press.

9 Smout AJ, Breedijk M, van der Zouw C, Akkermans LM: Physiological gastroesophageal reflux and esophageal motor activity studied with a new system for 24-hour recording and automated analysis. Dig Dis Sci 1989;34:372378.

10 Richter JE, Bradley LA, DeMeester TR, Wu WC: Normal 24-hour ambulatory esophageal $\mathrm{pH}$ values. Influence of study center, $\mathrm{pH}$ electrode, age and gender. Dig Dis Sci 1992;37: 849-856.
11 Bollschweiler E, Wolfgarten E, Putz B, Gutschow C, Holscher AH: Bile reflux into the stomach and the esophagus for volunteers older than 40 years. Digestion 2005;71:65-71.

12 Koek GH, Vos R, Flamen P, Sifrim D, Lammert F, Vanbilloen B, Janssens J, Tack J: Oesophageal clearance of acid and bile: A combined radionuclide, $\mathrm{pH}$, and $\mathrm{Bilitec}^{\circledR}$ study. Gut 2004;53:21-24.

13 Tack J, Vantrappen G: The aging oesophagus. Gut 1997;41:422-424.

14 Kahrilas PJ: The role of hiatus hernia in GERD. Yale J Biol Med 1999;72:101-111.

15 Tack J, Koek G, Demedts I, Sifrim D, Janssens J: Gastroesophageeal reflux disease poorly responsive to single-dose proton pump inhibitors in patients without Barrett's esophagus: Acid reflux, bile reflux, or both. Am J Gastroenterol 2004;99:981-988. 